\title{
Identifikasi Motivasi Pekerja Pada Proyek Konstruksi Di Kabupaten Aceh Barat
}

\author{
Zakia $^{* 1}$ \\ 1, Jurusan Teknik Sipil Universitas Teuku Umar, Alue Penyareng, Meulaboh, Aceh Barat \\ e-mail: ${ }^{* 1}$ zakia.mrk@gmail.com
}

\begin{abstract}
ABSTRAK
Aspek motivasi menjadi sangat penting untuk menigkatkan semangat dan kinerja para pekerja pada proyek konstruksi. Peningkatan kinerja ini menjadi tantangan penting di industri konstruksi di Indonesia.Konsepmotivasi yang di terapkan dalam suatu lingkungan kerja akan memberikan dukungan terhadap parapekerja. Oleh karena itu, diperlukan suatu konsep motivasi yang dapat diterapkan dalam lingkungan kerja. Tujuan penelitian ini adalah untuk mengidentifikasi dan menganalisis faktor-faktor yang mempengaruhi kinerja pekerja konstruksi dan merekomendasikan alternatif peningkatan motivasi pekerja pada proyek konstruksidi Kabupaten Aceh Barat. Penelitian dilakukan berdasarkan teori motivasi kerja yaitu teori kebutuhan hirarki kebutuhan Maslow. Metode yang digunakan dalam penelitian ini adalah deskriptif analisis.Hasil perhitungan penelitian ini menggunakan bantuan program komputer SPSS (Statistical Product and Service Solution) versi 16.00. uji validitas, uji reliabilitas, dan uji frekuensi dari analisis dapat diketahui bahwa bonus dan upah tambahan menjadi prioritas utama pada kebutuhan fisik dengan total nilai 135, program keselamatan kerja yang baik menjadi prioritas utama pada kebutuhan keamanan dan keselamatan dengan total nilai 130, hubungan yang baik dengan sesama pekerja menjadi prioritas utama pada kebutuhan sosial dengan total nilai 123, dapat menyelesaikan pekerjaan dengan baik menjadi prioritas utama pada kebutuhan penghargaan dengan total nilai 122, pengaturan jadwal pekerjaan yang baik menjadi prioritas utama pada kebutuhan akan jati diri dengan total nilai 115, sedangkan alternatif yang dapat dilakukanuntuk identifikasi motivasi pekerja konstruksi di Kabupatan Aceh Barat adalah dengan memberikan bonus dan upah tambahan ketika para pekerja dapat menyelesaikan pekerjaan sebelum target sebagai bentuk penghargaan.
\end{abstract}

\section{Katakunci: Pekerja, motivasi, SPSS}

\section{ABSTRACT}

Motivation aspect becomes very important to boost the spirit and performance of the workers on construction project. This performance improvement becomes an important challenge in the construction industry in Indonesia. The concept of motivation applied in a work environment will provide support to the worker. Therefore, we need a concept of motivation that can be applied in the work environment. The purpose of this study is to identify and analyze the factors that affect the performance of construction workers and recommend alternative motivation of employers to construction projects in West Aceh regency. The research is based on theoretical biotechnological yoruteorical needs of Maslow's needs. The method used in this research is descriptive analysis. The results of this research calculation using the help of computer program SPSS (Statistical Product and Service Solution) version 16.00. validity test, reliability test, and frequency test of the analysis can be seen that bonuses and additional wages are top priority on physical needs with a total value of 135, a good safety program is a top priority on security and safety needs with a total value of 130, a good relationship with fellow workers being the top priority of social needs with a total of 123 values, being able to complete the job well becomes a top priority on reward needs with a total score of 122, setting a good work schedule a top priority on the need for identity with a total value of 115, while alternatives which can be done to identify the motivation of construction workers in Kabupatan Aceh Barat is to provide bonuses and additional wages when workers can complete the work before the target as a form of appreciation.

Keywords : Workers, motivation, SPSS 


\section{PENDAHULUAN}

Proyek konstruksi adalah suatu rangkaian kegiatan yang berkaitan dengan upaya pembangunan suatu bangunan, yang nantinya akan difungsikan dengan berbagai kegiatan yang berhubungan dengan pemerintah maupun swasta. Proyek konstruksi dapat berlangsung dengan baik,salah satu factor pendukungnya adalah dengan adanya motivasi dan semangat kerja,sehingga keberhasilan suatu proyek dari segi disiplin dan waktu dapat direalisasikan.

Aspek motivasi menjadi sangat penting untuk menigkatkan semangat dan kinerja para pekerja pada proyek konstruksi. Peningkatan kinerja ini menjadi tantangan penting pada industri konstruksi di Indonesia (Soekiman, 2010). Oleh karena itu, pemahaman mengenai faktor-faktor yang mendukung motivasi para pekerja pada proyek konstruksi menjadi sangat penting agar pelaksanaan proyek konstruksi dapat berlangsung dengan baik.

Motivas ipekerja berpengaruh terhadap empat faktor penentu produktivitas pekerja, yaitu durasi usaha pekerja, intensetas usaha pekerja, efektifitas penggabungan usaha pekerja dengan teknologi dan sumber daya yang lain, dan efisiensi usaha pekerja.Konsep motivasi yang diterapkan dalam suatu lingkungan kerja akan memberikan dukungan terhadap para pekerja. Oleh karena itu, diperlukan

Suatu konsep motivasi yang dapat diterapkan dalam lingkungan kerja. Dalam hal ini, usaha yang di lakukan oleh seorang pekerja adalah perwujudan fisik motivasi, semakin tinggi motivasi pekerja, semakin tinggi usaha yang dilakukannya.

Penelitian yang dilakukan berlokasi di Kabupaten Aceh Barat, bertepatan pada dua lokasi penelitian yaitu Gedung Administrasi Fakultas yang berlokasi di Alue Peunyareng, Universitas Teuku Umar dan Gedung TK Binaan berlokasi di Jalan KLK Komplek Dinas Pendidikan. Gedung yang dipilih pada penelitian ini adalah Gedung kontruksi yang sedang masa proses pembangunan. Penelitian ini berlokasi di Kabupaten Aceh Barat. Seperti yang dapat dilihat pada Gambar 1.1.

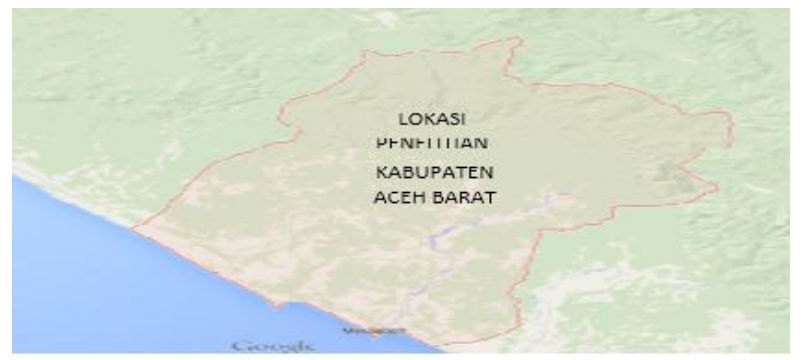

Gambar 1.1 : Peta Lokasi Penelitian Kab. Aceh Barat

Penelitian ini dilakukan berdasarkan teori motivasi kerja yaitu teori kebutuhan Moslow. Penelitian motivasi tenaga kerja konstruksi dilakukan pada jenjang keahlian mandor, tukang batu, tukang kayu, dan tukang besi. Penelitian dilakukan dengan mengambil beberapa sampel pada beberapa proyek pembangunan di kabupaten Aceh barat. Riset dilakukan dengan menggunakan kuesioner, responden menilai faktor-faktor motivasi demotivasi sesuai dengan keahlian mereka masing-masing.

\section{TINJAUAN PUSTAKA}

\subsection{Tinjauan Motivasi Secara Umum}

Semua proyek konstruksi menggunakan keterampilan manusiauntuk mencapai tujuan, mempersiapkan rencana, dan mengimplementasikan rencana-rencana tersebutuntuk mencapai tujuan proyek. ProjectManager, yang mengharapkan pekerjaan selesai melalui kerja sama dalam timproyek, harusmenaruhperhatianpadafaktormanusiadalammanajemenproyek, untuk menciptakan 
iklim yang baik dan komunikasi yang efektif.Iklim tersebut merupakan iklim yang dapat memotivasi seseorang dan memiliki komitmen untuk bekerja dengan kemampuan terbaik.

Secara keseluruhan, kesuksesan proyek tergantung pada motivasi dan performa dari semua tim proyek. Tim proyek yang memiliki motivasi tinggi memiliki ciri penghematan biaya yang besar, kualitas yang baik, produktivitas pekerja yang tinggi, kepuasan, dan moral.

Rendahnya motivasi akan menimbulkan konflik, tekanan, moral dan produktivitas yang rendah, dan terkadang kesalahan total dalam menafsirkan obyek dari pekerjaan proyek. Demikian sebaliknya apabila tim proyek memiliki motivasi, maka mereka akan melakukan yang terbaik dengan kualitas hasil pengerjaan yang baik (Verma,1996).

Salah satu cara yang dikenal untuk memuaskan kebutuhan para pekerja dengan teknik motivasi yang tepat. Yang dimaksud teknik motivasi yang tepat adalah yang di sesuaikan dengan presepsi yang bersangkutan dengan peringkat kebutuhan dan intensitas kebutuhan itu. Artinya tidak ada teknik motivasi yang begitu berlaku umum sehingga dapat diterapkan dengan cara yang sama untuk semua orang. Teknik motivasi yang efektif adalah teknik yang ditunjukan kepada dan disesuikan dengan kebutuhan individual. Sasaran adalah dengan akan tercapainya tujuan bersama antar pimpinan dengan para pekerja (Moslow, 1994).

\subsection{Definisi motivasi}

Motivasi seringkali didefinisikan sebagai:

- Proses rangsangan seseorang untuk bekerja mencapai obyek dari proyek dan di lain pihak memuaskan obyek personal;

- Bagian dalam (inner state) yang menyebabkan individual berperilaku untuk menyelesaikan tujuan akhir mereka, atau akibat yang ditimbulkan dari lingkungan kerja, sehingga menyebabkan orang dengan kesempatan-kesempatan yang ada memperoleh kepuasan psikologi, social dan ekonomi yang maksimum;

- Penentuan perilaku seseorang, yang dipengaruhi oleh kebutuhan manusia untuk mencapai obyek personal.

Motivasi adalah suatukonsep yang digunakan untuk menjelaskan tindakan pada atau di dalam suatu organisme untuk memulai (initiate) dan mengarahkan (direct) perilaku. Konsep motivasi ini juga dipakai untuk menjelaskan perbedaan-perbedaan dalam intensitas (intensity) perilaku. Perilaku dengan intensitas yang lebih besar dianggap sebagai hasil level motivasi yang lebih tinggi. Motivasi ini di wujudkan dengan tindakan untuk mendapatkan apa yang dimaksud dengan kepuasan terhadap kebutuhan-kebutuhan tersebut (Verma,1996).

Definisi-definisi tersebut mempunyai beberapa elemen dan ide-idwe yang bersifat secara umum, misalnya:

a. Motivasi mempengaruhi produktivitas;

b. Motivasi adalah proses intrinsik dan internal;

c. Motivasi mendorong orang-orang untuk mencapai tujuan;

d. Motivasi melibatkan kepuasan psikologi, social dan ekonomi;

e. Motivasi berarti suatu penciptaan situasi lingkungan yang membantu semua orang mencapai obyek dari pekerjaan, di lain pihak memperoleh kepuasan personal yang maksimum.

\subsection{Faktor-faktor Motivasi Kerja}

Penunjang agar terciptanya produktivitas tenaga kerja adalah terpenuhi dan terlaksana faktor-faktor motivasi kerja bagi setiap tenaga kerja. Untuk mendapatkan motivasi kerja yang dibutuhkan suatu landasan yaitu terdapatnya suatu motivator. Hal-hal yang dibutuhkan oleh motivator adalah sebagai berikut (Verma,1996):

Faktor-faktor tersebut dapat berupa:

1. Gaji yang baik, kondisi kerja, dan rekan kerja lain yang bersahabat; 
2. Makanan, Pakaian, dan tempat untuk berlindung untuk memenuhi kebutuhan psikologi yang dasar;

3. Keamanan pekerjaan atau bekerja pada industry dengan kondisi keuangan yang baik;

4. Kebutuhan untuk tantangan dan pertumbuhan.

\subsection{Kuesioner/Pertanyaan}

Menurut Azwar (1994), metode pengumpulan data dengan cara membagikan daftar pertanyaan sesuai dengan yang diteliti kepada responden. kuesioner adalah sejumlah pertanyaan tertulis yang digunakan untuk memperoleh informasi dari responden dalam arti laporan tentang pribadinya, atau hal-hal yang ia ketahui. Kuesioner dapat dibedakan menjadi beberapa jenis, yaitu:

- Kuesioner langsung, yaitu jika daftar pertanyaan diserahkan pada responden agar menjawab tentang dirinya.

- Chek list yaitu sebuah daftar pertanyaan dimana responden tinggal menghubungkan tanda $(\sqrt{ })$ pada kolom yang sesuai.

- Ranting Scala yaitu sebuah pertanyaan yang diikuti oleh kolom-kolom yang menunjukan tingkatan, misalnya mulai sangat baik sampai sangat kurang baik.

Penilaian dilakukan dengan skala linkert dimana responden diberi pilihan (option) yang kemudian tinggal memilih derajat kesetujuan/ketidak setujuannya atas pertanyaan yang diajukan.

Nilai dari skala linkert tersebut adalah :

a. Jawaban (SS) sangat setuju diberi nilai 4;

b. Jawaban (S) setuju diberi nilai 3;

c. Jawaban (KS) kurang setuju diberi nilai 2;

d. Jawaban (TS) tidak setuju diberi nilai 1;

e. Jawaban (STS) sangat tidak setuju diberi nilai 0 .

\subsection{Jumlah Sampel}

Menurut Sri Rahayu (2005), menyatakan sebagai pedoman umum dalam pengambilan sampel yang repsentatif adalah jika populasi dibawah 100 dipergunakan sampel sebesar 50\% dan jika diatas 100 maka diambil sebesar 15-20\% sampel atau jumlah sampel yang dianjurkan dalam pengertian SPSS adalah 50 sampai 100 baris (antara 50 sampai 100 sampel). Selanjutnya jika variabel yang dipergunakan dalam penelitian itu banyak maka ukuran sampelnya minimal $10 \mathrm{kali}$ atau lebih dari jumlah faktor atau variabel yang digunakan dalam penelitian.

\subsubsection{Karakteristik responden}

Karakteristik responden akan di bagi dari tingkat keahlian berbagai bidang pekerjaan seperti Mandor, Tukang Batu, Tukang Besi dan Tukang Kayu. Karakteristik responden untuk mengetahui persentasi (\%) dari dari pekerja seperti.

a. Karakteristik responden berdasarkan tingkat keahlian;

b. Karakteristik responden berdasarkan tingkat pendidikan;

c. Karakteristik responden berdasarkan usia;

d. Karakteristik responden berdasarkan lama pengalaman di bidang konstruksi. 


\subsubsection{Analisis Validitas dan Reliabilitas}

Untuk menguji kehandalan dari kuesioner yang digunakan adalah dengan menguji :

a) Validitas Kuesioner

Menurut Azwar (1994), sebuah kuesioner bisa dikatakan valid jika kuesioner tersebut benar-benar mengukur apa yang harus diukur. Pengukuran validitas ini dilakukan dengan menghitung korelasi antara total jawaban responden terhadap setiap pertanyaan. Pengolahan data dengan menggunakan bantuan program SPSS (Statistical Product and Service Solution). Tinggi rendahnya validitas suatu angket dihitung dengan teknik korelasi, dengan rumus :

$$
\mathrm{r}=\frac{N \sum X-\left(\sum X\right)\left(\sum Y\right)}{\sqrt{\left[N \sum X^{2}-\left(\sum X\right)^{2}\right]\left[N \sum Y^{2}-\left(\sum Y\right)^{2}\right]}}
$$

dimana :

$\mathrm{r} \quad=$ Koefisien korelasi setiap variabel

$\mathrm{N}=$ Jumlah sampel

$\mathrm{X}$ = Skor masing-masing item

$\mathrm{Y}=$ Skor total

Kriteria uji validitas secara singkat (rule of tumb) adalah 0,3. Jika korelasi sudah lebih besar dari 0,3 maka kuesioner yang dibuat dikategorikan valid (Husen, 2003).

b) Uji Reliabilitas

Reliabilitas adalah derajat ketepatan, ketelitian atau keakuratan yang ditunjukkan oleh instrumen pengukuran. Selain itu, juga untuk memastikan bahwa responden cukup konsisten dalam memberikan jawaban (reliabilitas). Analisis keandalan butir bertujuan untuk menguji konsitensi butir-butir pertanyaan dalam mengungkap indikator. Reliabilitas test dapat diestimasikan dengan menggunakan analisis Alpa Cronbach, dengan rumus (Husein, 2003).

$$
r 11=\left\lfloor\frac{K}{K-1}\right\rfloor 1-\left(\frac{\sum a^{2}}{\sigma^{2}}\right)
$$

dimana :

r11 = Reliabilitas yang dicari

$\mathrm{k} \quad=$ Banyaknya butir pertanyaan

$\sum \mathrm{ab}^{2}=$ Jumlah varian butir

$\sigma \mathrm{t} \quad=$ Varian total

Menurut Santosa dan Ashari (2005), bahwa penilaian responden dianggap reliabel jika alpa lebih besar dari 0,6. Pengolahan data dengan menggunakan bantuan program SPSS.

\subsubsection{Analisis Frekuensi}

Analisis frekuensi adalah daftar yang menunjukan penggolongan suatu data yang termasuk kedalam setiap golongan, digunakan mengatur atau menyusun/meringkas data. Frekuensi dibagi menjadi dua macam yaitu: frekuensi bilangan dan frekuensi kategori berisikan data kualitatif yang didasarkan sifat-sifat dan lain-lain Mencari data frekuensi "Aturan sturges"

$$
\mathrm{K}=1+3,3 \log \mathrm{n}
$$

dimana :

$\mathrm{k} \quad=$ Banyaknya kelas yang dibentuk 
Vol. 4 No.1 April 2018

pp. $96-109$

$\mathrm{n} \quad=$ Banyaknya pengamatan

\subsubsection{Cara Kerja SPSS}

Dasarnya komputer berfungsi mengelola data menjadi informasi yang berguna bagi pengguna komputer. Data yang diolah dimasukkan sebagai input, kemudian dengan proses pengolahan data oleh komputrer dihasilkan output berupa informasi untuk kegunaan lebih lanjut. Gambar 2.2 cara kerja komputer dengan program SPSS (Statistical Product and Service Solution) dalam mengola data. Dapat dilihat pada Gambar 2.2.

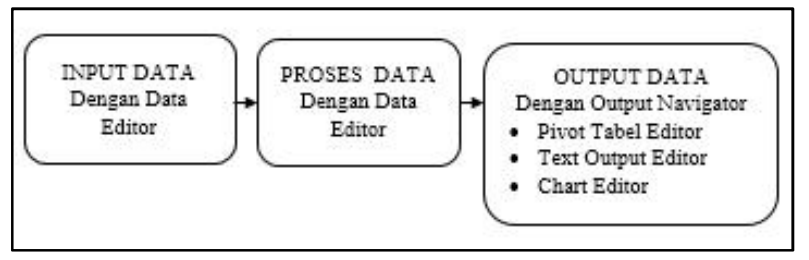

Gambar 2.1 : Cara Kerja SPSS

Keterangan :

Sumber : Wulansari, 2012

1. Data dimasukkan melalui data editor yang otomatis muncul dilayar SPSS pada saat SPSS dibuka.

2. Data yang telah diinput kemudian diproses melalui data editor

3. Hasil pengolahan data muncul di layar window yang lain dari SPSS, yaitu Output Navigator. Lalu tampilanya dapat berupa:
a. Tulisan
b. Tabel
c. Grafik

\section{METODOLOGI PENELITIAN}

\subsection{Metode Pengumpulan Data}

Data yang digunakan dalam penelitian ini adalah data primer, yaitu data yang diambil atau dikumpulkan langsung dilapangan. Adapun data yang akan diambil yaitu :

a. Karakteristik responden berdasarkan tingkat keahlian;

b. Karakteristik responden berdasarkan tingkat pendidikan;

c. Karakteristik responden berdasarkan tingkat usia;

d. Karakteristik berdasarkan lama pengalaman dibidang konstruksi;

e. Tinjauan motivasi pekerja konstruksi terhadap teori kebutuhanAbraham H Maslow.

Data tersebut diambil dengan cara memberikan tertulis, yaitu kumpulan pertanyaan yang diajukan secara tertulis kepada seorang responden, dan cara menjawabnya juga dilakukan dengan tertulis.

\subsection{Metode Analisis Data}

Kuesioner dalam penelitian ini digunakan untuk mengetahui motivasi pekerja proyek kostruksi di Kabupaten Aceh Barat dengan sampel yaitu Mandor, Tukang Batu, Tukang Kayu dan Tukang Besi. Penelitian ini pengumpulan datanya akan menggunakan jenis kuesioner langsung yaitu jika daftar pertanyaan diserahkan pada responden agar menjawab tentang dirinya dengan tertulis dan kuesioner tertutup sejumlah pertanyaan tertulis yang sudah disediakan jawabanya sehingga responden tinggal memilih. Chek list yaitu sebuah daftar pertanyaan dimana responden tinggal menghubungkan tanda $(\sqrt{ })$ pada kolom yang sesuai. 
Data primer dalam penelitian ini berupa jawaban kuesioner responden dari pertanyaanpertanyaan yang telah dibuat oleh peneliti yang diisi oleh Pekerja Konstruksi di Kabupaten Aceh Barat. Adapun data primer yang diambil dalam penelitian ini yaitu :

a. Tingkat keahlian pekerja;

b. Tingkat pendidikan pekerja;

c. Tingkat usia pekerja;

d. Lama pengalaman dibidang konstruksi;

e. Tinjauan motivasi pekerja konstruksi berupa jawaban yang tinggal Chek list nya.

\section{HASIL DAN PEMBAHASAN}

\subsection{Deskripsi responden}

Populasi dalam penelitian ini adalah 34 responden yaitu dari pihak Mandor, Tukang Batu, Tukang Besi dan Tukang Kayu, 34 responden diambil dari pekerja yang berada di 2 lokasi Gedung Administrasi Fakultas dan Gedung TK Binaan di Kabupaten Aceh Barat. Dikarenakan besarnya sampel dalam penelitian ini sebanyak 50\% dari jumlah keseluruhan pekerja, sehingga 50\% x $68=$ 34. Jadi sampel dalam penelitian ini sebanyak 34 pekerja.

\section{A. Karakteristik responden berdasarkan tingkat keahlian}

Karakteristik responden akan di bagi dari tingkat keahlian berbagai bidang seperti Mandor, Tukang Batu, Tukang Besi dan Tukang Kayu proyek konstruksi pada 2 tempat lokasi proyek konstruksi di Kabupaten Aceh Barat yaitu Gedung Administrasi Fakultas dan Gedung TK Binaan. Pada penelitian ini didapatkan hasil karakteristik tingkat keahlian yang dapat dilihat pada Tabel 4.1 dan presentasi dalam bentuk gambar dapat dilihat pada Gambar 4.1.

Tabel 4.1 Karakterisistik responden berdasarkan tingkat keahlian

\begin{tabular}{|c|c|c|c|}
\hline NO & Jabatan & Jumlah Responden & Persentase $\%$ \\
\hline 1 & Mandor & 2 & 5,9 \\
\hline 2 & Tukang Batu & 16 & 47,2 \\
\hline 3 & Tukang Besi & 7 & 20,65 \\
\hline 4 & Tukang Kayu & 9 & 26,55 \\
\hline & Total & 34 & 100 \\
\hline
\end{tabular}

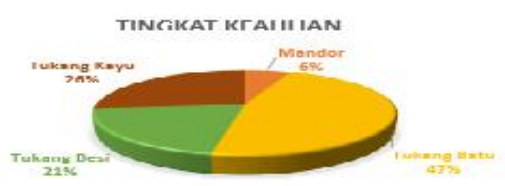

Gambar 4.1 Karakteristik responden berdasarkan tingkat keahlian

Berdasarkan karakteristik responden berdasarkan tingkat keahlian dari 34 responden yang terdiri dari berbagai bidang seperti Mandor, Tukang Batu, Tukang Besi dan Tukang Kayu dari 100 $\%$ di dua lokasi didapatkan presentasinya untuk 5,9\% dari 2 orang Mandor, 47,2 \% dari 16 orang Tukang Batu, 20,65 \% dari 7 orang Tukang Besi, dan 26,55 \% dari 9 orang Tukang Kayu.

\section{B. Karakteristik responden berdasarkan tingkat pendidikan}

Tingkat pendidikan pada responden diperlukan untuk mengetahui dalam penelitian ini sejauh mana tingkat pendidikanya yang di ajukan kepada responden. Dari hasil penelitian ini dapat dilihat pada Tabel 4.2 dan presentasi dalam bentuk gambar dapat dilihat pada Gambar 4.2. 
Tabel 4.2 Karakteristik berdasarkan tingkat pendidikan

\begin{tabular}{|c|c|c|c|}
\hline NO & Pendidikan & Jumlah Responden & Persentase $\%$ \\
\hline 1 & SD & 8 & 23,6 \\
\hline 2 & SMP & 15 & 44,25 \\
\hline 3 & SMA/STM/SMK & 6 & 17,7 \\
\hline 4 & Tidak Berselkolah & 5 & 14,75 \\
\hline & Total & 34 & 100 \\
\hline
\end{tabular}

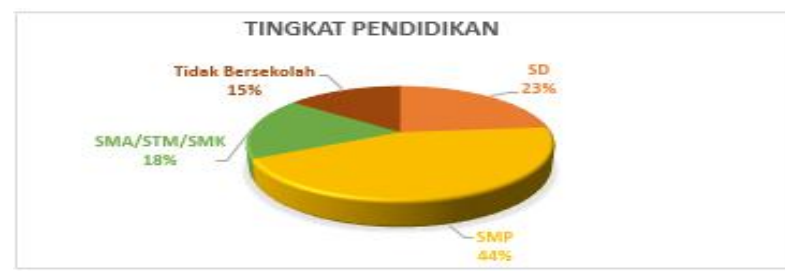

Gambar 4.2 Karakteristik responden berdasarkan tingkat pendidikan

Berdasarkan karakteristik responden berdasarkan tingkat pendidikan dari 34 responden yang terdiri dari berbagai bidang seperti Mandor, Tukang Batu, Tukang Besi dan Tukang Kayu dari $100 \%$ di dua lokasi didapatkan presentasinya untuk $23,6 \%$ dari 8 orang berpendidikan SD, $44,25 \%$ dari 15 orang berpendidikan SMP, 17,7 \% dari 6 orang berpendidikan SMA/STM/SMK, dan $14,75 \%$ dari 5 orang tidak bersekolah.

\section{Karakteristik responden berdasarkan usia}

Usia produktifitas pada suatu pekerjaan konstruksi sangat mempengaruhi dalam kelancaran suatu proyek konstruksi, maka dari itu pada penelitian ini usia termasuk sebagai tinjauan dalam penelitian. Hasil dari tinjauan yang didapat dari responden dapat dilihat pada Tabel 4.3 dan presentasi dalam bentuk gambar dapat dilihat pada Gambar 4.3.

Tabel 4.3 Karakteristik berdasarkan Usia

\begin{tabular}{|c|c|c|c|}
\hline NO & Usia (Tahun) & Jumlah Responden & Persentase \% \\
\hline 1 & $17-26$ & 9 & 26,55 \\
\hline 2 & $27-36$ & 10 & 29,5 \\
\hline 3 & $37-46$ & 6 & 17,7 \\
\hline 4 & Lebilh dari 46 & 9 & 26,55 \\
\hline \multicolumn{4}{|r|}{} \\
\hline
\end{tabular}

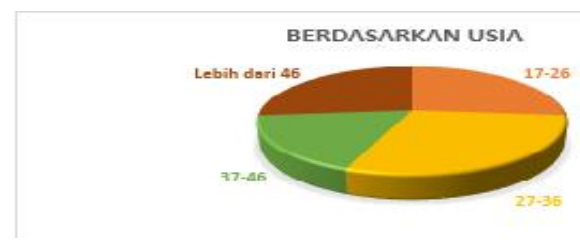

Gambar 4.3 Karakteristik responden berdasarkan usia

Berdasarkan karakteristik responden berdasarkan usia dari 34 responden yang terdiri dari berbagai bidang seperti Mandor, Tukang Batu, Tukang Besi dan Tukang Kayu dari $100 \%$ di dua 
lokasi didapatkan presentasinya untuk 26,55\% dari 9 orang berusia 17 - 26 tahun, 29,5\% dari 10 orang berusia 27 - 36 tahun, $17,7 \%$ dari 6 orang berusia 37 - 46 tahun, dan $26,55 \%$ dari 9 orang berusia lebih dari 46 tahun.

\section{Karakteristik responden berdasarkan lama pengalaman di bidang konstruksi}

Pengalaman kerja merupakan tingkat pemahaman seorang pekerja pada pekerjaan konstruksi, dikarenakan semakin lama pengalaman pekerja dalam pekerjaan jasa konstruksi maka semakin baik hasil yang didapat. Hasil dari tinjauan yang didapat dari responden dapat dilihat pada Tabel 4.4 dan presentasi dalam bentuk gambar dapat dilihat pada Gambar 4.4.

Tabel 4.4 Karakteristik berdasarkan lama pengalaman di bidang konstruksi

\begin{tabular}{|c|c|c|c|}
\hline NO & $\begin{array}{c}\text { Lama pengalaman di } \\
\text { bidang konstruksi } \\
\text { (tahun) }\end{array}$ & Jumlah Responden & Persentase \% \\
\hline 1 & O sampai 1 & 4 & 11,8 \\
\hline 2 & 1 sampai 10 & 14 & 41,3 \\
\hline 3 & 10 sampai 20 & 10 & 29,5 \\
\hline 4 & Lebih dari 20 & 6 & 17,7 \\
\hline & Total & 34 & 100 \\
\hline
\end{tabular}

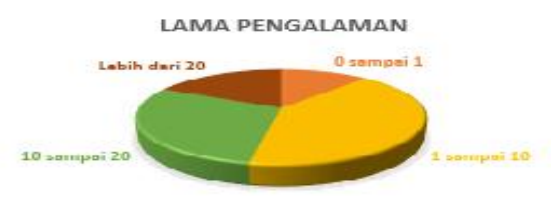

Gambar 4.4 Karakteristik responden berdasarkan lama pengalaman

\section{E. Analisa data tinjauan identifikasi motivasi pekerja}

Analisa data pada tinjauan motivasi pekerja untuk menguji kuesioner untuk kegunaan analisis uji validitas dan reliabilitas. Analisis data yang digunakan adalah analisis frekuensi. Tinjauan motivasi pekerja konstruksi terhadap teori kebutuhan Abraham H Maslow dapat dilihat pada Tabel 4.5

Tabel 4.5 Tinjauan identifikasi motivasi pekerja

\begin{tabular}{|l|l|l|}
\hline No & \multicolumn{1}{|l|}{$\begin{array}{c}\text { HALL-HAL YANG MEMPENGARUHI ANDA UNTUK } \\
\text { LEBIH GIAT DAN TERMOTIVASI UNTUK BEKERJA }\end{array}$} & KODE \\
\hline KEBUTUHAN FISIK (X1) & \\
\hline 1. & Setuju dengan bonus dan upah tambahan? & Item_1 \\
\hline 2. & Setuju dengan upah saat ini ? & Item_2 \\
\hline 3. & Fasilitas tempat tinggal baik ? & Item_3 \\
\hline 4. & Setuju dengan kerja lembur? & Item_4 \\
\hline KEBUTUHAN KEAMANA DAN KENYAMANAN (X2) & \\
\hline 5. & Program keselamatan kerja baik? & Item_5 \\
\hline 6. & Kondisi tempat kerja baik? & Item_6 \\
\hline 7. & Pekerjaan berjalan baik? & Item_7 \\
\hline 8. & Pengawasan berjalan baik ? & Item_8 \\
\hline KEBUTUHAN SOSIAL (X3) & \\
\hline 9. & Hubungan terjalin baik dengan atasan? & Item_99 \\
\hline 10. & Hubungan berjalan baik dengan sesama pekerja? & Item_10 \\
\hline 11. & Program pengarahan kerja sudah berjalan baik dilapangan? & Item_11 \\
\hline 12. & Setujukah dengan program pelatihan kerja? & Item_12 \\
\hline KEBUTUHAN AK.AN PENGHARGAAN (X4) & \\
\hline 13. & Diterimakah usulan dari atasan? & Item_13 \\
\hline 14. & Setuju dengan pekerjaan yang menantang? & Item_14 \\
\hline 15. & Setuju apabila dapat menyelesaikan pekerjaan dengan baik? & Item_15 \\
\hline 16. & Pekerjaan yang menarik dan memberi harapan? & Item_16 \\
\hline KEBUTUHAN AKAN JATI DIRI (X5) & \\
\hline 17. & Potensi kemampuan yang lebih ? & Item_17 \\
\hline 18. & Bagaimana dengan pengaturan suplematerial? & Item_18 \\
\hline 19. & Jadwal pekerjaan berjalan dengan baik? & Item_19 \\
\hline 20. & Jelaskah sasaran pekerjaan? & Item_20 \\
\hline
\end{tabular}




\subsection{Uji Validitas dan Reliabilitas}

\section{A. Uji validitas}

Uji validitas di gunakan untuk mengukur kevalidtan jawaban responden terhadap setiap pertanyaan, dari keseluruhan 20 item pertanyaan yang diberikan dalam bentuk kuesioner yang disampaikan kepada responden dilakukan uji validitas terhadap setiap butir pertanyaan dalam kelompok variabel dengan menggunakan program SPSS versi 16.00.

Hasil uji validitas setiap item pertanyaan identifikasi motivasi pekerja proyek konstruksi dapat dilihat pada Tabel 4.6. Jika korelasi sudah lebih besar dari 0,3 maka kuesioner yang dibuat dikategorikan valid.

Tabel 4.6 Validitas item pertanyaan identifikasi motivasi pekerja proyek konstruksi

\begin{tabular}{|c|c|c|c|}
\hline No & $\begin{array}{l}\text { HAL-HAL YANG MEMPENGARUHI ANDA UNTUK } \\
\text { LEBIH GIAT DAN TERMOTIVASI UNTUK } \\
\text { BEKERJA }\end{array}$ & $\begin{array}{c}\text { Nilai } \\
\text { Validitas }\end{array}$ & Keterangar \\
\hline \multicolumn{4}{|c|}{ KEBUTUHAN FISIK (X1) } \\
\hline 1. & Setuju dengan bonus dan upah tambahan? & $0,822>0,3$ & Valid \\
\hline 2. & Setuju dengan upah saat ini ? & $0,400>0,3$ & Valid \\
\hline 3. & Fasilitas tempat tinggal baik ? & $0,355>0,3$ & Valid \\
\hline 4. & Setuju dengan kerja lembur ? & $0,067<0,3$ & Tidizk Valid \\
\hline \multicolumn{4}{|c|}{ KEBUTUHAN KEAMANA DAN KENYAMANAN $(\mathrm{X} 2)$} \\
\hline 5. & Program keselamatan kerja baik? & $0,575>0,3$ & Valid \\
\hline 6. & Kondisi tempat kerja baik? & $0,659>0,3$ & Valid \\
\hline 7. & Pekerjaan berjalan baik ? & $0,561>0,3$ & Valid \\
\hline 8. & Pengawasan berjalan baik? & $0,759>0,3$ & Valid \\
\hline \multicolumn{4}{|c|}{ KEBUTUHAN SOSIAL (X3) } \\
\hline 9. & Hubungan terjalin baik dengan atasan? & $0,642>0,3$ & Valid \\
\hline 10. & Hubungan berjalan baik dengan sesama pekerja ? & $0,567>0,3$ & Valid \\
\hline 11. & Program pengarahan kerja sudah berjalan baik dilapangan ? & $0,769>0,3$ & Valid \\
\hline 12. & Setujukah dengan program pelatihan kerja ? & $0,783>0,3$ & Valid \\
\hline \multicolumn{4}{|c|}{ KEBUTUHAN AKAN PENGHARGAAN (X4) } \\
\hline 13. & Diterimakah usulan dari atasan? & $0,662>0,3$ & Valid \\
\hline 14. & Setuju dengan pekerjaan yang menantang ? & $0,388>0,3$ & Valid \\
\hline 15. & Setuju apabila dapat menyelesaikan pekerjaan dengan baik ? & $0.413>0.3$ & Valid \\
\hline 16. & Pekerjaan yang menarik dan memberi harapan ? & $-0,209<0,3$ & Tidizk Valid \\
\hline \multicolumn{4}{|c|}{ KEBUTUHAN AKAN JATI DIRI (X5) } \\
\hline 17. & Potensi kemampuan yang lebih? & $0,244<0,3$ & Tidzk Valid \\
\hline 18. & Bagaimana dengan pengaturan suplematerial ? & $0,783>0,3$ & Valid \\
\hline 19. & Jadwal pekerjaan berjalan dengan baik ? & $0,684>0,3$ & Valid \\
\hline 20. & Jelaskah sasaran pekerjaan? & $0,789>0,3$ & Valid \\
\hline
\end{tabular}

Diketahui 17 item pertanyaan dari 20 pertanyaan mengenai "Identifikasi Motivasi Pekerja Pada Proyek Konstruksi di Kabupaten Aceh barat" menyatakan valid nilai Corrected Item Total Correlation $>0,3$, sedangkan 2 item pertanyaan lainya yaitu item 4 setuju dengan kerja lembur $(0,067)$ dan item 17 potensi kemampuan yang lebih $(0,244)$ tidak valid dikarenakan nilai Corrected Item Total Correlation < 0,3, artinya mempunyai korelasi atau hubungan terhadap tinjauan identifikasi motivasi pekerja konstruksi tetapi hubungan tersebut rendah. Sedangkan item 16 yaitu pekerjaan yang menarik dan memberi harapan dengan nilai $-0,209<0,3$ artinya mempunyai korelasi atau hubungan terhadap identifikasi motivasi pekerja proyek konstruksi tersebut bernilai negatif.

\section{B. Uji reliabilitas}

Uji reliabilitas digunakan dengan tujuan untuk mengetahui sifat alat ukur yang digunakan, dalam arti apakah alat ukur tersebut akurat, stabil dan konsisten. Instrumen yang digunakan dalam penelitian ini dikatakan andal (reliable) apabila memiliki cronbach'alpha if item deleted. hasil uji reliabilitas dari variabel-variabel penelitian yang menggunakan cronbach'alpha dengan bantuan SPSS versi 16.00 .

Hasil uji reliabilitas item pertanyaan identifikasi motivasi pekerja proyek konstruksi dapat dilihat pada Tabel 4.7. penilaian responden dianggap reliabel jika alpa ( ) lebih besar dari 0,6. 
Vol. 4 No.1 April 2018

pp. $96-109$

Tabel 4.7 Reliabilitas item pertanyaan identifikasi motivasi pekerja proyek konstruksi

\begin{tabular}{|c|c|c|c|}
\hline No & $\begin{array}{l}\text { HAL-HAL YANG MEMPENGARUHI ANDA UNTUK } \\
\text { LEBIH GIAT DAN TERMOTIVASI UNTUK } \\
\text { BEKERJA }\end{array}$ & $\begin{array}{l}\text { Croubach's } \\
\text { Alpha if } \\
\text { Item } \\
\text { Deleted } \\
\end{array}$ & Keterangan \\
\hline \multicolumn{4}{|c|}{ KEBUTUHAN FISIK } \\
\hline 1. & Setuju dengan bonus dan upeh tambahan? & $0,355>0,6$ & Reliabel \\
\hline 2. & Setuju dengan upah saat ini? & $0,871>0,6$ & Reliabel \\
\hline 3. & Fasilitas tempat tinggal baik ? & $0,873>0,6$ & Reliabel \\
\hline 4. & Setuju dengan kerja lembur? & $0,884>0,6$ & Reliabe! \\
\hline \multicolumn{4}{|c|}{ KEBUTUHAN KEAMANA DAN KENYAMANAN } \\
\hline 5. & Program keselamatan kerja baik? & $0,868>0,6$ & Reliabel \\
\hline 6. & Kondiai tempat kerja bzik? & $0,863>0,6$ & Reliabel \\
\hline 7. & Pekerjaan berjaian baik? & $0,867>0,6$ & Reliabel \\
\hline 8. & Pengawasan berjalan baik? & $0,359>0,6$ & Reliabel \\
\hline \multicolumn{4}{|c|}{ KEBUTUHAN SOSIAL } \\
\hline 9. & Hubungen terjalin baik dengan atzaan? & $0,864>0,6$ & Reliabel \\
\hline 10. & Hubungan berjalan baik dengan sesama pekerja ? & $0,867>0,6$ & Reliabel \\
\hline 11. & Program pengarahan kerja sudah berjalan baik dilapangan ? & $0,357>0,6$ & Reliabel \\
\hline 12. & Setujukah dengan program pelatihan kerja ? & $0,856>0,6$ & Reliabel \\
\hline \multicolumn{4}{|c|}{ KEBUTUHAN AKAN PENGHARGAAN } \\
\hline 13. & Diterimzkah usulan dari atzaan? & $0,864>0,6$ & Reliabel \\
\hline 14. & Setuju dengan pakerjaan yang menantang ? & $0,872>0,6$ & Reliabel \\
\hline 15. & Setuju apabila dzpat menyeleszikan pakerjaan dengan baik ? & $0,872>0,6$ & Reliabe! \\
\hline 16. & Pekerjaan yang menarik dan menberi harapan ? & $0,888>0,6$ & Reliabe! \\
\hline \multicolumn{4}{|c|}{ KEBUTUHAN AKAN JATI DIRI } \\
\hline 17. & Potenai kemampuan yang lebih? & $0,883>0,6$ & Reliabel \\
\hline 18. & Bagzimana dengan pengaturan suplemzterial? & $0,856>0,6$ & Reliabel \\
\hline 19. & Jadval pekerjaan berjalan dengan baik? & $0,862>0,6$ & Reliabe! \\
\hline 20. & Jelaskah sasaran pekerjazn? & $0,856>0,6$ & Reliabel \\
\hline
\end{tabular}

Dari tabel 4.7 dapat diketahui semua item pertanyaan dalam kelompok mengenai faktor penyebab keterlambatan proyek konstruksi dilingkup pemerintah Kabupaten Aceh Barat menunjukkan nilai yang reliabel karena cronbach'alpa if Item D eleted $>0,60$, artinya 34 responden dalam pengisian kuesioner 20 item pertanyaan tersebut akurat, stabil dan konsisten.

\subsection{Analisis Frekuensi}

Analisis frekuensi adalah daftar yang menunjukkan penggolongan suatu data yang termasuk ke dalam setiap golongan, digunakan untuk mengatur atau menyusun/meringkaskan data.

Tahapan perhitungan frekuensi penelitian ini dengan menggunakan program SPSS V.16. Tahap pertama dari data di variable view tulis nilai total dari setiap bagian pertanyaan dengan diasumsikan X1, X2, X3, X4 dan X5, Gambar 4.13. lalu klik data view untuk memasukakan skor nilai total setiap bagian pertanyaan.

Hasil uji frekuensi dari variabel-variabel penelitian yang menggunakan bantuan program SPSS versi 16 dapat dilihat pada Tabel 4.8 sedangkan untuk frekuensi tertinggi mengenai kebutuhan yang mempengaruhi motivasi pada proyek konstruksi dapat dilihat pada Tabel 4.8. 
Tabel 4.8 Frekuensi tertinggi mengenai kebutuhan yang mempengaruhi motivasi pekerja proyek konstruksi

\begin{tabular}{|c|l|c|l|}
\hline No & $\begin{array}{c}\text { Hal-hal yang mempengaruhi } \\
\text { anda untuk lebih giat dan } \\
\text { termotivasi untuk bekerja }\end{array}$ & $\begin{array}{l}\text { Total } \\
\text { nilai }\end{array}$ & \multicolumn{1}{|c|}{ Level } \\
\hline 1 & Bonus dan upah tambahan & 135 & Kebutuhan Fisik (X1) \\
\hline 2 & Program keselamatan kerja baik & 130 & $\begin{array}{l}\text { Kebutuhan Keamanan dan } \\
\text { Kenyamanan (X2) }\end{array}$ \\
\hline 3 & $\begin{array}{l}\text { Hubungan berjalan baik dengan } \\
\text { sesama pekerja }\end{array}$ & 123 & Kebutuhan Sosial (X3) \\
\hline 4 & $\begin{array}{l}\text { Dapat menyelesaikan pekerjaan } \\
\text { dengan baik }\end{array}$ & 122 & $\begin{array}{l}\text { Kebutuhan Akan } \\
\text { Penghargaan (X4) }\end{array}$ \\
\hline 5 & $\begin{array}{l}\text { Jadwal pekerjaan berjalan dengan } \\
\text { baik }\end{array}$ & 115 & $\begin{array}{l}\text { Kebuthan Akan Jati Diri } \\
\text { (X5) }\end{array}$ \\
\hline
\end{tabular}

Pada bagian berikut ini akan dikemukakan pembahasan mengenai analisis dan hasil perhitungan yang berhubungan dengan studi. Hal-hal yang dibahas mencakup penentuan peringkat tingkat kebutuhan motivasi tenaga kerja pada jenjang keahlian di Kabupaten Aceh Barat.

\section{Analisis validitas}

Analisis validitas dapat diketahui bahwa 17 item mengenai "Identifikasi Motivasi Pekerja Pada Proyek Konstruksi di Kabupaten Aceh barat" menyatakan valid nilai Corrected Item Total Correlation $>0,3$, sedangkan 2 item pertanyaan lainya yaitu item 4 setuju dengan kerja lembur $(0,067)$ dan item 17 potensi kemampuan yang lebih $(0,244)$ tidak valid dikarenakan nilai Corrected Item Total Correlation < 0,3, artinya mempunyai korelasi atau hubungan terhadap tinjauan identifikasi motivasi pekerja konstruksi tetapi hubungan tersebut rendah. Sedangkan item 16 yaitu pekerjaan yang menarik dan memberi harapan dengan nilai $(-0,209)<0,3$ artinya mempunyai korelasi atau hubungan terhadap identifikasi motivasi pekerja proyek konstruksi tersebut bernilai negatif.

\section{Analisis reliabilitas}

Analisis reliabilitas dapat diketahui bahwa semua butir pertanyaan dalam kelompok mengenai Motivasi Pekerja Pada Proyek Konstruksi di Kabupaten Aceh Barat menunjukkan nilai cronbach'alpha if item deleted $>0,60$, artinya 34 responden dalam pengisian kuesioner 20 item pertanyaan tersebut akurat, stabil dan konsisten.

\section{Analisis frekuensi}

Analisis frekuensi dapat diketahui 5 frekuensi tertinggi mengenai kebutuhan yang memepengaruhi motivasi pekerja proyek adalah bonus dan upah tambahan menjadi prioritas utama pada kebutuhan fisik dengan total nilai 135, program keselamatan kerja yang baik menjadi prioritas utama pada kebutuhan keamanan dan keselamatan dengan total nilai 130, hubungan yang baik dengan sesama pekerja menjadi prioritas utama pada kebutuhan sosial dengan total nilai 123, dapat menyelesaikan pekerjaan dengan baik menjadi prioritas utama pada kebutuhan penghargaan dengan total nilai 122, pengaturan jadwal pekerjaan yang baik menjadi prioritas utama pada kebutuhan akan jati diri dengan total nilai 115 . 


\section{KESIMPULAN DAN SARAN}

\section{$5.1 \quad$ Kesimpulan}

Berdasarkan analisis data dan pembahasannya yang telah dilakukan dalam penelitian ini dapat ditarik kesimpulan sebagai berikut :

1. Manfaat dalam penelitian ini tentang motivasi para pekerja dalam berbagai bidang keahlian yaitu Sebagai media belajar untuk memahami motivasi pekerjapada proyek-proyek konstruksi.

2. Kebutuhan yang menjadi prioritas utama yang mempengaruhi motivasi pekerja proyek konstruksi di Kabupaten Aceh Barat adalah bonus dan upah tambahan menjadi prioritas utama pada kebutuhan fisik dengan total nilai 135, program keselamatan kerja yang baik menjadi prioritas utama pada kebutuhan keamanan dan keselamatan dengan total nilai 130, hubungan yang baik dengan sesama pekerja menjadi prioritas utama pada kebutuhan sosial dengan total nilai 123 , dapat menyelesaikan pekerjaan dengan baik menjadi prioritas utama pada kebutuhan penghargaan dengan total nilai 122, pengaturan jadwal pekerjaan yang baik menjadi prioritas utama pada kebutuhan akan jati diri dengan total nilai 115 .

3. Alternatif yang dapat dilakukan untuk meningkatkan motivasi pekerja konstruksi pada 2 tempat lokasi proyek konstruksi yaitu Gedung Administrasi Fakultas dan Gedung TK Binaan di Kabupaten Aceh Barat adalah dengan memberikan bonus dan upah tambahan ketika para pekerja konstruksi dapat menyelesaikan pekerjaan sebelum targetnya.

\subsection{Saran}

Adapun saran yang mungkin dapat dijadikan sebagai bahan pertimbangan yaitu :

1. Diharapkan dalam penelitian ini dapat menambah wawasan keilmuan bidang konstruksi pada umumnya dan manajemen proyek konstruksi pada khususnya, terutama tentang motivasi para pekerja.

2. Diharapkan untuk pihak pelaksana karena kebutuhan fisik menjadi prioritas utama yang mempengaruhi "Identifikasi Motivasi Pekerja Pada Proyek Konstruksi di Kabupaten Aceh Barat" maka perlu memfokuskan para pekerja secara fisik yaitu kompensasi yang cukup, kebutuhan keselamatan yaitu keamanan dan keselamatan, kebutuhan sosial, kebutuhan penghargaan, dan kebutuhan akan jati diri yaitu pengaturan jadwal pekerjaan yang baik.

3. Penelitian ini disarankan untuk dilanjutkan dengan penelitian yang bertujuan menilai aplikasi konsep motivasi yang diterapkan di lingkungan proyek konstruksi, dengan membandingkan antara proyek konstruksi yang menerapkan konsep motivasi dengan yang belum menerapkan konsep motivasi. Dengan penelitian lanjutan tentang konsep motivasi di lingkungan proyek konstruksi dapat mampu memberikan penelitian bahwa penerapan konsep motivasi dapat memberikan keuntungan-keuntungan terutama dalam pencapaian tujuan proyek

\section{DAFTAR KEPUSTAKAAN}

1. Andi, dan Djondoko., H. 2004, Motivasi Pekerja Pada Beberapa Proyek Konstruksi di Surabaya. Jurnal Teknik Sipil, Fakultas Teknik Sipil dan Perencanaan-Universitas Kristen Petra, 6(2), 80-87.

2. Azwar., 1994. Sikap Manusia, Teori dan Pengukurannya. Pustaka Pelajar, Yogyakarta.

3. Google Map 2014, kabupaten Aceh Barat, viewed Desemser 2015, available from internet. http://www.leuserfoundation.org/index.php._Desember 2015 
4. Hidayat, F., 2007, Motivasi Pekerja pada Proyek Konstruksi di Kota Bandung, Jurnal Penelitian Media Teknik Sipil. Universitas NegeriSebelas Maret. Volume IX Nomor 1 Januari 2009 ISSN-1412-0976.

5. Husein., 2003. Riset Pemasaran dan Perilaku Konsumen, Gramedia Pustaka Utama, Jakarta.

6. Maslow, A.H., 1994. Motivasi dan Kepribadian Daya Manusia". Pustaka Binaan Pressindo, Theary, Simon and Schuster, New York.

7. Purnomo., 2011. Motivasi Site Manager Pada Proyek Konstruksi di Kota Bandung, Bandung, Fakultas Teknik Jurusan Teknik Sipil, Universitas Katolik Parahyangan.

8. Santosa.P.B. \& Ashari., 2005. Analisis Statistik Dengan Microsoft Excel \& SPSS, Penerbit ANDI, Yogyakarta.

9. Soekirman., 2010. Faktor-faktor yang Memepengaruhi Motivasi Kerja Pekerja Terampil di Industri, Fakultas Teknik Jurusan Teknik Sipil, Universitas Katolik Parahyangan, Bandung.

10. Rahayu., 2005. SPSS Versi 12.00 Dalam Riset Pemasaran, CV. ALFABETA, Bandung.

11. Verma,V.K.,(1996). The Human Aspect of Project Management, Human Resource Skills for the Project Manager, Volume Two. Project Management Institute, Upper Darby, U.S.A.

Wulansari., 2015. Tinjauan Motivasi Pekerja Proyek Konstruksi Terhadap Teori Kebutuhan Abraham H Maslow, Fakultas Teknik Jurusan Teknik Sipil, Universitas Sebelas Maret, Surakarta. 